\title{
Wave Runup and Overtopping at Seawalls Built on Land and in Very Shallow Water
}

\author{
Hajime Mase, M.ASCE ${ }^{1}$; Takashi Tamada ${ }^{2}$; Tomohiro Yasuda ${ }^{3}$; Terence S. Hedges ${ }^{4}$; \\ and Maria T. Reis ${ }^{5}$
}

\begin{abstract}
The current study proposes prediction formulas both for random wave runup and mean overtopping discharge at seawalls constructed on land or in very shallow water. Although several existing formulas for runup and overtopping use the incident wave characteristics at the toes of seawalls, this study adopts the equivalent deepwater wave characteristics and an imaginary seawall slope for easy application of the formulas, especially in relation to seawalls constructed on land. The prediction formulas for overtopping use the predicted runup values. For the wave runup prediction formulas two sets of experimental data are used; i.e., a new set of data and the data obtained in a previous study. For the wave overtopping prediction formulas, the experimental data measured in a previous study are used. Comparisons with measurements show good performances of both new prediction methods. DOI: 10.1061/(ASCE)WW.1943-5460.0000199. (C) 2013 American Society of Civil Engineers.
\end{abstract}

CE Database subject headings: Wave runup; Wave overtopping; Sea walls; Slopes; Shallow water.

Author keywords: Wave runup; Wave overtopping; Seawalls near shoreline; Imaginary seawall slope.

\section{Introduction}

The crest levels of storm surge barriers and seawalls in Japan are based on either the estimated wave runup or the wave overtopping discharge; see the Technical Standards and Commentaries for Port and Harbour Facilities in Japan (TSC) issued by The Overseas Coastal Area Development Institute of Japan (OCDI 2007). The TSC states that the selection of wave runup or overtopping as the design criterion should depend on the location of the structure. Accordingly, when a seawall is built in the sea, the design crest level is based on the permissible wave overtopping discharge; however, when it is constructed on the shore, the required crest level is governed by the wave runup. The TSC also states that the design safety level may differ depending on the selection of wave runup or overtopping as the design criterion. While the design of Japanese coastal defenses using runup and overtopping criteria has not yet been wholly standardized, the processes of wave runup and overtopping have been studied for some considerable time.

The diagram and formula for wave runup in Nakamura et al. (1972) are often used in Japan. However, their approach was formulated

${ }^{1}$ Professor, Disaster Prevention Research Institute, Kyoto Univ., Gokasho, Uji, Kyoto 611-0011, Japan (corresponding author). E-mail address: mase.hajime.5c@kyoto-u.ac.jp

${ }^{2}$ Senior Engineer, IDEA Consultants, Inc., 2-2-2 Hayabuchi, Tsuduki, Yokohama, Kanagawa 224-0025, Japan.

${ }^{3}$ Assistant Professor, Disaster Prevention Research Institute, Kyoto Univ., Gokasho, Uji, Kyoto 611-0011, Japan.

${ }^{4}$ Honorary Research Fellow, School of Engineering, Univ. of Liverpool, Brownlow Hill, Liverpool L69 3GH, U.K.

${ }^{5}$ Research Officer, National Civil Engineering Laboratory, Harbours and Maritime Structures Division, Ave. do Brasil 101, Lisbon 1700-066, Portugal.

Note. This manuscript was submitted on October 7, 2012; approved on February 27, 2013; published online on March 6, 2013. Discussion period open until February 1, 2014; separate discussions must be submitted for individual papers. This paper is part of the Journal of Waterway, Port, Coastal, and Ocean Engineering, Vol. 139, No. 5, September 1, 2013. (CASCE, ISSN 0733-950X/2013/5-346-357/\$25.00. only for regular waves, and runup predictions using the significant wave height as input are generally different from the observed random wave values (Tamada et al. 2009). Runup formulas used in Europe [e.g., de Waal and van der Meer 1993; Technical Advisory Committee on Flood Defence (TAW) 2002] and in the United States [e.g., the Coastal Engineering Manual of the U.S. Army Corps of Engineers (USACE 2002)] account for the random behavior of waves; additionally, in the previously mentioned formulas the effects of any nonuniformity in the cross sections of seawalls are considered by using an equivalent uniform slope.

The overtopping of sea defenses by random waves can be estimated from design diagrams (e.g., Goda et al. 1975; Tamada et al. 2002) or by using various formulas (e.g., Takayama et al. 1982; USACE 2002; Pullen et al. 2007; Goda 2009). However, in applying overtopping models, it is important to be aware of where the input wave conditions are specified. The most common are (1) offshore, (2) at the toe of the foreshore slope, and (3) at the toe of the structure itself. Hedges and Reis (2004) discussed the features of the various locations at which the wave conditions may be specified. However, when a structure is built in very shallow water or on land, the wave height at its toe is not easy to define. In this case, it must be determined from numerical simulations or experiments.

The current study addresses the issue of linking wave runup and overtopping and establishes a prediction methodology that can be easily applied to field conditions in Japan and elsewhere. There have been earlier studies on the relationship between runup and overtopping [e.g., in Japan (Tominaga 1972; Mase et al. 2003) and in Europe (Hedges and Reis 1998; Reis et al. 2008)]. In these studies, the estimated wave runup was used to predict wave overtopping because the two processes are closely related. However, these prediction formulas cannot easily be applied to many of the seawalls built on land and in very shallow water.

Here, a prediction method for random wave runup on seawalls constructed near or above the shoreline is proposed. To ease its application, the proposed method uses deepwater wave characteristics as input and it adopts the concept of an imaginary uniform slope for evaluating the surf similarity parameter. The wave overtopping 
discharge is established from the estimated runup. For the wave runup prediction formulas two sets of experimental data are used; i.e., a new set of data and the data of Mase et al. (2004). For the wave overtopping prediction formulas, the experimental data of Tamada et al. (2002) are used. The predictions of both the runup and overtopping are compared with the experimental results to assess their performance.

\section{Characteristics of Seawalls in Japan}

Fig. 1 summarizes the number of seawalls in Japan according to their front slope [data from the River Bureau of Japan (RBJ 1990)]. It shows that, at the time of the survey, a slope of 1:0.5 $(\cot \alpha=0.5)$ was most commonly adopted when a steep seawall was constructed, while a slope of 1:3 $(\cot \alpha=3.0)$ was most often built to provide a gentler front slope. Although the data are old, the present situation is unlikely to be very different because coastal conditions in Japan have not changed significantly since the 1980s.

Fig. 2 shows the number of Japanese construction sites where, in the 1980s, the toes of seawalls were close to or above the shoreline at the highest, high-water level (HHWL) [National Association of Sea Coast (NASC) 1982]. Negative depth values indicate that the seawalls were located on land. Eighteen of the 63 cases were on land, while 31 cases had their toes in less than 3.0-m-deep water at the HHWL. Once again, the situation is unlikely to have changed markedly. Fig. 3 shows a seawall and the foreshore on the Nabae Coast in Muroto City, Kochi Prefecture, Japan. Part of this seawall (a 30-m-long identifiable in Photograph 1) was destroyed by waves during Typhoon Tokage in 2004. The cross section of the wall is shown in Fig. 4. Its front slope is 1:0.5 and the toe of the structure is located above the HHWL. Even during Tokyo Peil (TP) $+2.86 \mathrm{~m}$, the sea level was lower than the toe of the seawall. Nevertheless, high waves ran up the foreshore and attacked and destroyed the seawall parapet over a 30-m length. The broken concrete plunged into houses behind the seawall, resulting in three casualties; however, the destruction was not caused by the direct action of waves on the wall but by the wave runup.

\section{Existing Formulas for Wave Runup and Wave Overtopping}

In the subsequent sections, some existing formulas for predicting random wave runup and overtopping on smooth slopes are summarized.

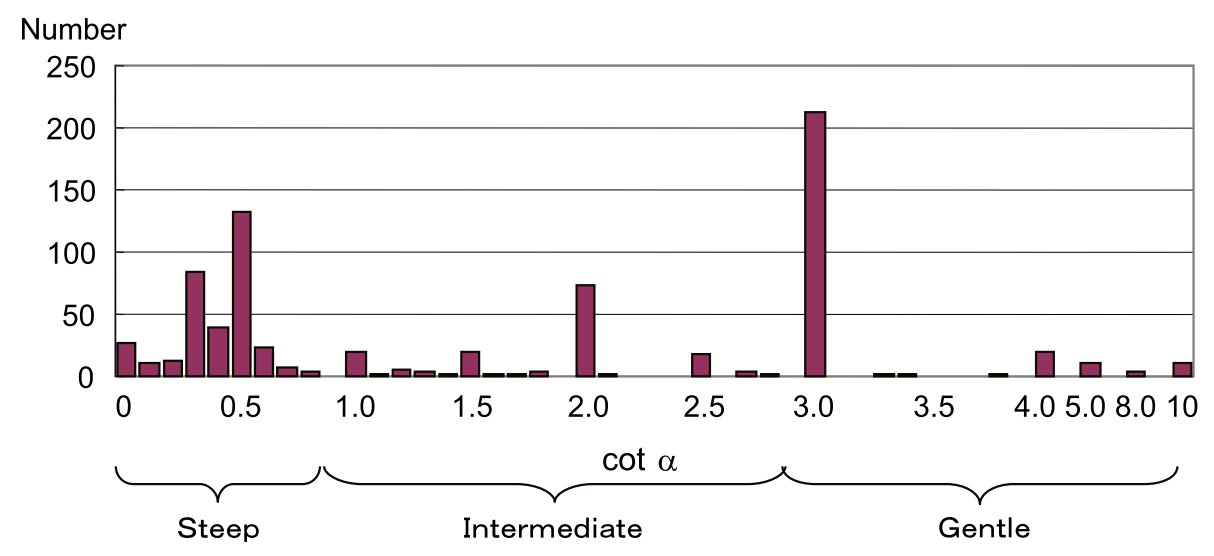

Fig. 1. Number of seawalls in Japan (grouped by their front slope)

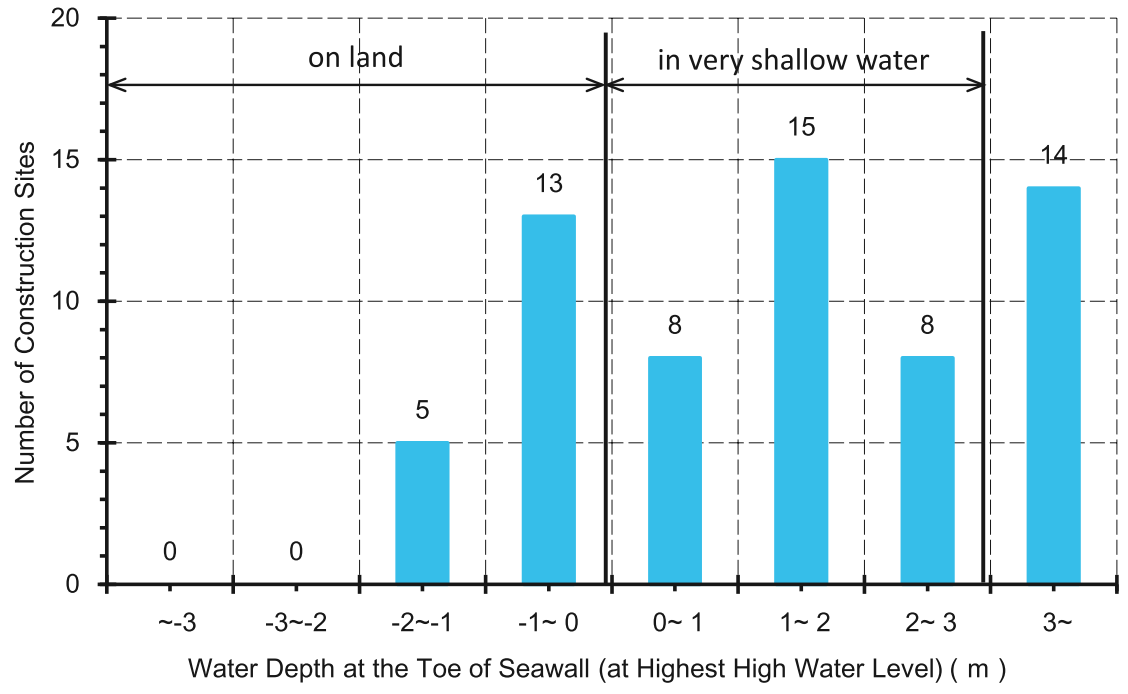

Fig. 2. Number of construction sites in Japan (grouped by the water depth at the toes of the seawalls) 


\section{Formulas for Wave Runup}

Coastal Engineering Manual (USACE 2002)

$$
\begin{aligned}
& R_{2 \%} / H_{s}=1.6 \xi_{p} \text { for } \xi_{p} \leq 2.5 \\
& R_{2 \%} / H_{s}=-0.2 \xi_{p}+4.5 \text { for } 2.5<\xi_{p}<9.0
\end{aligned}
$$

where $R_{2 \%}=$ runup exceeded by $2 \%$ of the incident waves, $H_{s}=$ significant wave height at the toe of the structure, and $\xi_{p}=$ surf similarity parameter defined using $H_{s}$ and the spectral peak period, $T_{p}$. When the number of incident waves is 200 , the fourth largest runup is taken as $R_{2} \%$.

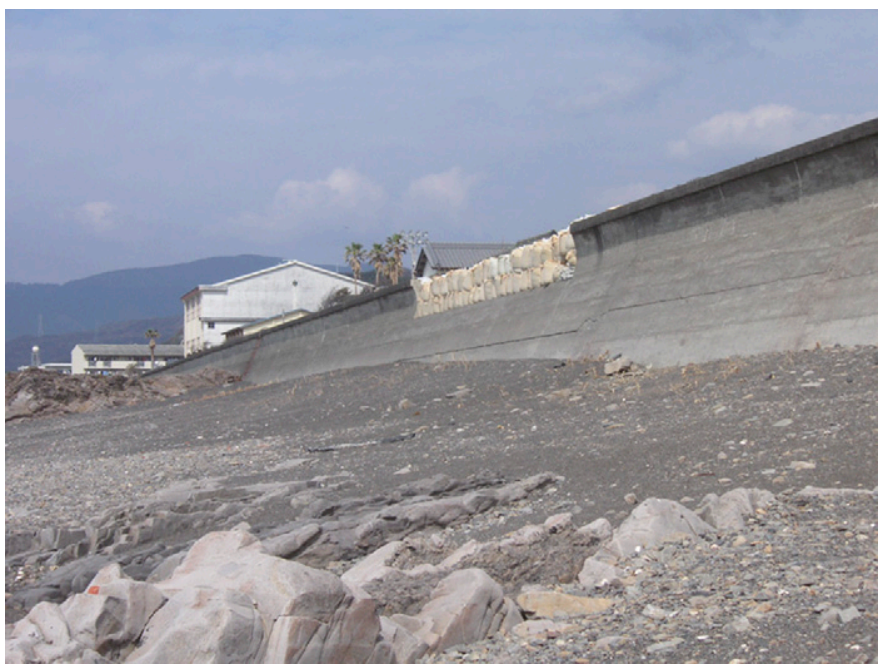

Fig. 3. View of the foreshore and seawall constructed on land (Nabae in Muroto City, Kochi Prefecture, Japan) (photograph by Hajime Mase)
In the present paper, the number of runups is taken to be equal to the number of incident waves (as in USACE 2002). However, when the foreshore and front slope of the seawall are gentle, the number of runups is smaller than the number of incident waves because the uprush from some waves is overtaken by others or the backrush from one wave destroys a subsequent uprush. In this case, the one-to-one correspondence between incident waves and runups no longer holds (Mase and Iwagaki 1985).

Technical Advisory Committee on Flood Defense (TAW 2002) $R_{2 \%} / H_{m 0}=1.75 \xi_{m}$; with a maximum given by

$$
R_{2 \%} / H_{m 0}=4.3-1.6 / \sqrt{\xi_{m}}
$$

where $H_{\mathrm{m} 0}=$ spectral significant wave height at the toe of the structure, and $\xi_{m}=$ surf similarity parameter defined using $H_{\mathrm{m} 0}$ and a spectral-based wave period, $T_{m-1,0} \approx T_{p} / 1.1$. A seawall having a nonuniform front slope is treated by using an equivalent uniform value (an imaginary slope), as shown in Fig. 5. Because this definition requires the evaluation of $R_{2} \%$, both the equivalent slope and $R_{2} \%$ must be found through a process of iteration. Eq. (2) incorporate a small safety margin. Without this safety margin, the coefficients $1.75,4.3$, and 1.6 are replaced by $1.65,4.0$, and 1.5 , respectively (Pullen et al. 2007).

de Waal and van der Meer (1993)

$$
\begin{aligned}
& R_{2} \% / H_{s}=1.5 \xi_{p} \text { for } \xi_{p} \leq 2.0 \\
& R_{2} \% / H_{s}=3.0 \text { for } 2.0<\xi_{p}
\end{aligned}
$$

The de Waal and van der Meer (1993) equivalent uniform slope for the front of a seawall is defined in Fig. 6. The difference from Fig. 5 is in

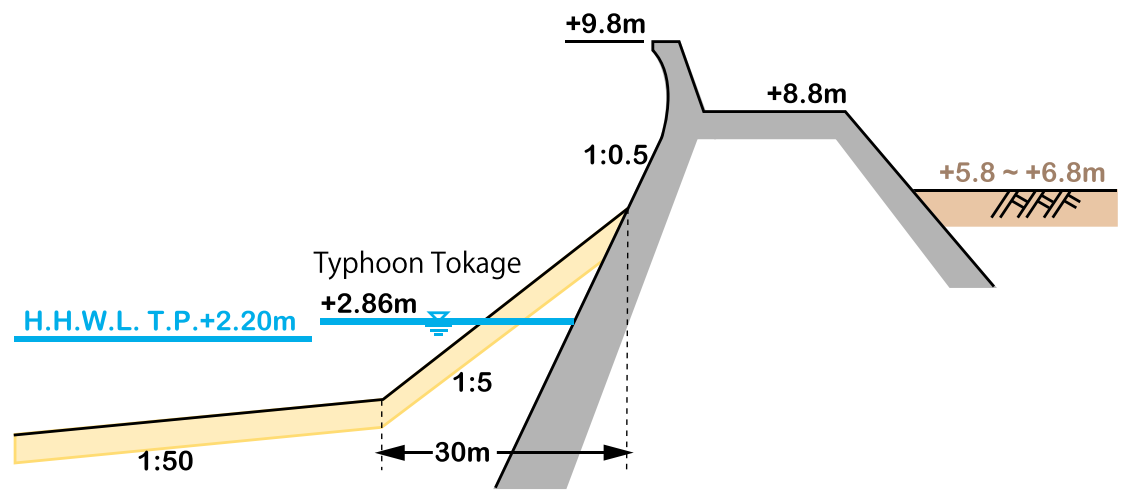

Fig. 4. Cross section of the foreshore and seawall on the Nabae coast in Muroto City

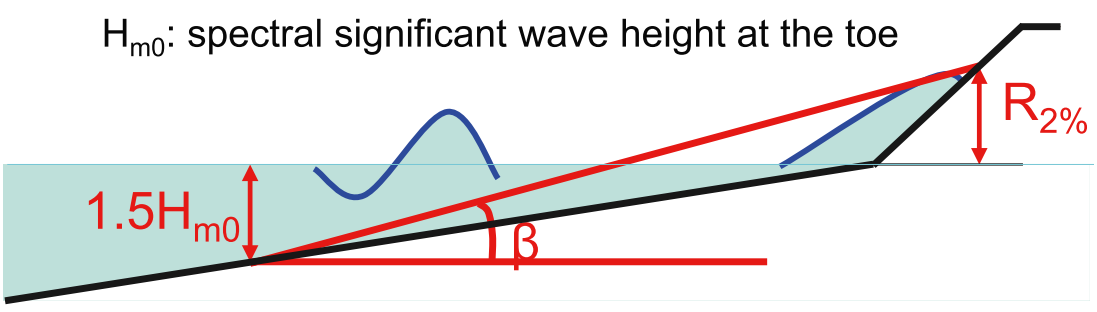

Fig. 5. Equivalent uniform front slope (according to TAW 2002) 


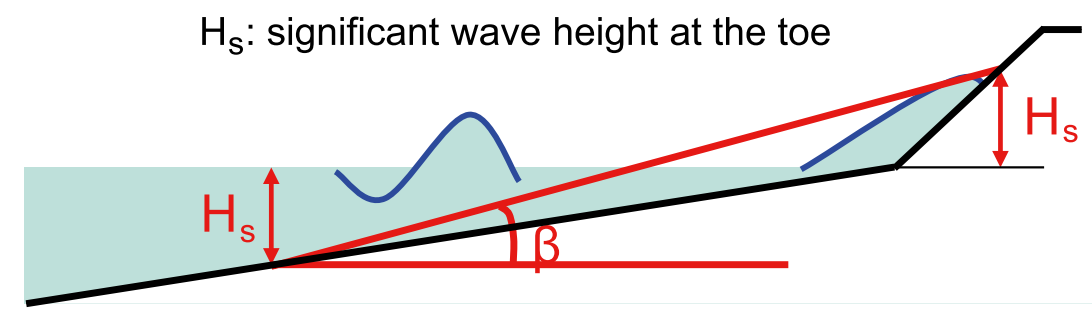

Fig. 6. Equivalent uniform front slope (according to de Waal and van der Meer 1993)

the two points delineating this slope, which in this case is being defined from $1.0 H_{s}$ below to $1.0 H_{s}$ above the still-water level.

\section{Hedges and Mase (2004)}

$$
R_{\mathrm{char}} / H_{S}=S_{\mathrm{char}} / H_{S}+c \cdot \xi_{p} \text { for } \xi_{p} \leq 2.2 \text { approx }
$$

where $R_{\text {char }}=$ value characterizing the magnitude of the runup, such as $R_{2 \%}, R_{1 / 10}$, or $R_{1 / 3}$; and $S_{\text {char }}=$ minimum value of $R_{\text {char }}$ as the front slope approaches (but does not reach) zero. Here, $R_{1 / 10}$ and $R_{1 / 3}=$ averages of the highest one-tenth and the highest one-third of the runups, respectively. Finally, $c=$ coefficient established from experimental data; its value changes depending upon the parameters chosen to characterize the runup and the incident waves. Values of $S_{\text {char }}$ and $c$ are given in Hedges and Mase (2004), where they show that, in cases in which the surf similarity parameter, $\xi_{p}$, is less than 2.0 , there is little difference in the prediction of runup values, regardless of whether offshore significant wave heights or corresponding values at the toe of a slope (but unaffected by wave breaking) are used.

Despite the general usefulness of Eqs. (1)-(4) elsewhere in the world, they cannot readily be applied to many of the seawalls in Japan because of the fact that in the equations the wave height at the toe of the structure is considered. In Japan, many seawalls are built near to the shoreline or on land. Therefore, in this study, the significant height of the incident waves in deep water is considered. Of course, the effects of refraction, wave-current interaction, and other wave processes occurring between the selected offshore location and the seawall must be accounted for (Hedges and Reis 2004) by using a suitable wave transformation model allowing for all relevant wave processes between the offshore boundary and the seawall (see, for example, the subsequent section on the wave breaking depth of random waves).

\section{Formulas for Wave Overtopping}

Although there are various overtopping formulas to predict the mean discharge, the formulas of Owen (1980), van der Meer and Janssen (1995), and Hedges and Reis (1998) are cited here. The first two formulas have the following exponential form:

$$
Q^{*}=A \exp \left(-B R^{*}\right)
$$

where $Q^{*}=$ dimensionless mean overtopping discharge, $R^{*}=$ dimensionless freeboard, and $A$ and $B=$ empirical coefficients. Eq. (5) predicts zero overtopping discharge only when $R^{*}$ becomes infinite.

\section{Owen (1980) Equation}

$$
\frac{Q}{T_{m} g H_{s}}=A \exp \left(-B \frac{R_{c}}{T_{m} \sqrt{g H_{s}}}\right)
$$

where $Q=$ mean overtopping discharge per unit length of seawall, $g=$ gravitational acceleration, $T_{m}=$ mean zero-crossing wave period, and $R_{c}=$ seawall freeboard. A reduction factor may be applied to account for slope roughness. In Owen's formula, $H_{s}$ is the significant wave height at the toe of a foreshore sloping uniformly seaward to a depth unaffected by wave breaking and not the value at the toe of the structure. Coefficients $A$ and $B$ are given for uniform front slopes of 1:1-1:5, although physical modeling was undertaken only for slopes of $1: 1,1: 2$, and 1:4.

van der Meer and Janssen (1995) Equation

$$
\frac{Q}{\sqrt{g H_{s}^{3}}}= \begin{cases}\frac{0.06 \xi_{p}}{\sqrt{\tan \alpha}} \exp \left(-5.2 \frac{R_{c}}{\xi_{p} H_{s}}\right) & \text { for } \xi_{p}<2 \\ 0.2 \exp \left(-2.6 \frac{R_{c}}{H_{s}}\right) & \text { for } \xi_{p}>2\end{cases}
$$

where $H_{s}=$ significant wave height at the toe of the seawall's front slope and $\alpha=$ angle of the front slope measured from the horizontal. Four reduction factors may be incorporated in the formulas to account for the effects of slope roughness, a berm, a shallow foreshore (depth-limited waves), and oblique wave attack (both short and long crested). Coefficients 0.06 and 5.2 in Eq. (7) have subsequently been updated to 0.067 and 4.75 (Pullen et al. 2007).

\section{Hedges and Reis (1998) Equation}

Hedges and Reis (1998) proposed a semiempirical formula based on an overtopping theory for regular waves developed by Kikkawa et al. (1968). This formula assumes that the seawall acts as a weir, and that the instantaneous discharge may be described by the weir formula. The form of the Hedges and Reis equation is as follows:

$$
\begin{array}{ll}
\frac{Q}{\sqrt{g R_{\max }^{3}}}=A\left(1-\frac{R_{c}}{R_{\max }}\right)^{B} & \text { for } 0<\frac{R_{c}}{R_{\max }}<1 \\
\frac{Q}{\sqrt{g R_{\max }^{3}}}=0 & \text { for } \frac{R_{c}}{R_{\max }} \geq 1
\end{array}
$$

The most recent values for coefficients $A$ and $B$ are given in Reis et al. (2008) in which the maximum runup, $R_{\max }$, is also defined as a function of $H_{s}$ and $\xi_{p}$, with $H_{s}$ defined at the toe of a foreshore sloping uniformly seaward to a depth unaffected by wave breaking.

\section{Wave Runup at a Seawall Built on Land and in Very Shallow Water}

\section{Imaginary Slope}

Because the front slope of a seawall is often nonuniform, an imaginary (or equivalent uniform) slope is sometimes used for estimating 
wave runup and overtopping. Saville (1958) first proposed such an imaginary slope, defined as a line connecting two points; i.e., one on the seabed at the wave breaking point and the other at the limit of wave uprush. Because the runup depends on the slope, and the imaginary slope is initially unknown, an iterative procedure is required to obtain both the imaginary slope and the runup. Two possible definitions of the imaginary slope are shown in Figs. 5 and 6. However, in this study, an imaginary slope that takes into consideration the cross-sectional configuration of the foreshore and seawall was used, as shown in Fig. 7 (following Nakamura et al. 1972). There are many formulas for predicting the water depth, $h_{b}$, at the onset of breaking for regular waves; however, here, an equivalent value for random waves is required for consistency with the present objective of establishing the runup and overtopping of random waves.

\section{Wave Breaking Depth of Random Waves}

The wave transformation model of Mase and Kirby (1993) was used for simplicity and accuracy in estimating $h_{b}$ for random waves. A total of 190 cases were run by changing the incident significant wave heights and periods (with the Bretschneider-Mitsuyasu spectrum and wave steepnesses of 0.002-0.07) and using uniform bottom slopes of 1:10, 1:20, 1:30, and 1:100. Table 1 summarizes the calculation conditions.

Fig. 8 shows a diagram of the dimensionless wave breaking depth, $h_{b} / H_{o}$, against the offshore significant wave steepness, $H_{o} / L_{o}$, for various values of the bottom slope, in which the curves fitted to the calculated values are also drawn. Here, $H_{o}$ is the offshore significant wave height and $L_{o}=g T_{o}^{2} / 2 \pi$, in which $T_{o}$ is the offshore significant wave period, defined as the average period of the highest one-third of the offshore waves. Most offshore wave information is currently given in terms of frequency-domain parameters, such as the peak spectral period and the mean spectral period. Timedomain periods, such as the significant wave period $T_{o}$ used in this paper, may be estimated from frequency-domain periods if the spectral shape is known (see Goda 2000).

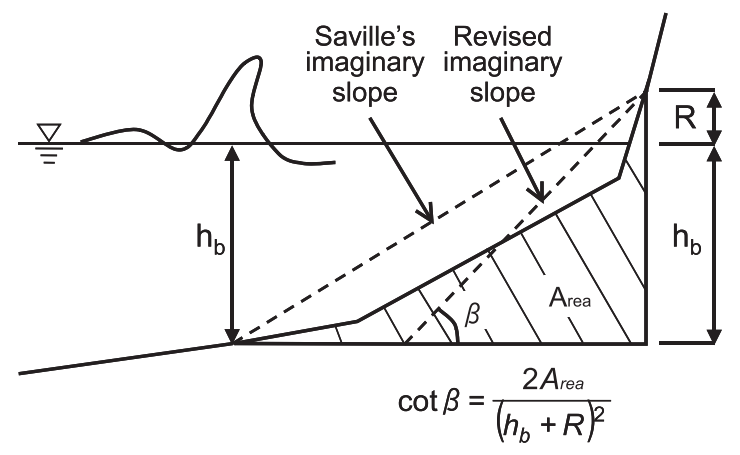

Fig. 7. Imaginary slope of foreshore and seawall used in this study (data from Nakamura et al. 1972)

Table 1. Summary of Calculation Conditions of Wave Breaking Depth of Random Waves (Values Are in Prototype Scale)

\begin{tabular}{ll}
\hline Condition & \multicolumn{1}{c}{ Value } \\
\hline Wave spectrum & Bretschneider-Mitsuyasu \\
Wave height $H_{o}(\mathrm{~m})$ & $0.37-4.48$ \\
Wave period $T_{o}(\mathrm{~s})$ & $6.0-10.0$ \\
Wave steepness $H_{o} / L_{o}$ & $0.002-0.07$ \\
Water depth $h(\mathrm{~m})$ & 30,60 \\
Sea bottom slope $\tan \theta$ & $1 / 10,1 / 20,1 / 30,1 / 100$ \\
\hline
\end{tabular}

The present wave breaking depth is defined as the water depth where the significant wave height becomes $7 \%$ smaller than that calculated without an energy dissipation term in the Mase and Kirby (1993) model. However, the peak in the significant height of random waves is unclear except for waves having very small steepnesses. Even so, all of the calculated results are well represented by the fitted curves, despite the differences in the wave heights and periods. Whenever a wave breaking depth is required for other slope angles, including imaginary values for nonuniform slopes, use of the fitted curves means that the calculation is both simple and rapid.

\section{Hydraulic Experiments and the Formulation of New Equations for Wave Runup}

Two sets of experimental data were used to formulate the new equations for wave runup. One of the sets of experiments was new and was conducted in a wave flume that was 50-m long, 1.0-m wide, and 1.2-m deep, equipped with an absorbing wave generator. The target model scale was 1:50. Three cases of beach topography were constructed, and seawalls with a nearly vertical front slope of 1:0.5 and a gentler slope of 1:3 were used in the experiments, as shown in Fig. 9.

The water depths in the offshore, uniform section of the wave flume were either 45 or $43 \mathrm{~cm}$ (prototype values of 22.5 and $21.5 \mathrm{~m}$ ). The corresponding water depths at the toes of the seawalls were either 0 or $-2 \mathrm{~cm}$, depending on the offshore water depth. A runup meter, $70 \mathrm{~cm}$ in length, was set at $3 \mathrm{~mm}$ above the face of each seawall. The peaks of the runup oscillations measured by the runup meter were compared with observed values captured on a video recorder. Random waves used in the experiments had a BretschneiderMitsuyasu-type spectrum. The target significant wave heights were 6.0 and $12.0 \mathrm{~cm}$ (prototype values of 3.0 and $6.0 \mathrm{~m}$ ), and the significant wave periods were 1.3, 1.7, and $2.1 \mathrm{~s}$ (prototype values of 9.0, 12.0 , and $15.0 \mathrm{~s}$ ). The number of individual waves in each experiment was about 200.

Another data set was obtained from the experiments of Mase et al. (2004) to examine the characteristics of random wave runup on seawalls located close to a shoreline. In that study, by adopting a scale of 1:45, models of artificial reefs and seawalls were installed in a wave flume. The water depths in the offshore, uniform section of the wave flume were $45,42.5$, or $40 \mathrm{~cm}$. At the landward end of a 1:20 beach slope, seawalls with slopes of either 1:0.5 or 1:3 were installed. The adopted data in the present paper are those without a reef in front of the seawalls. The experimental conditions obtained from both sets of data and the corresponding case numbers are summarized in Tables 2 and 3. Several wave conditions were generated for each case number.

Figs. 10-12 show the values of $R_{2 \%}, R_{1 / 10}$, and $R_{1 / 3}$, normalized by the deepwater significant wave height, $H_{o}$, plotted against the surf similarity parameter using the imaginary slope, $\tan \beta$, defined in Fig. 7. (Cases 3 and 4 do not appear in Fig. 12 because there were too

Table 2. Summary of New and Mase et al. (2004) Experimental Conditions (Values Are in Model Scale)

\begin{tabular}{ll}
\hline Condition & \multicolumn{1}{c}{ Value } \\
\hline Model scale & $1 / 45,1 / 50$ \\
Wave spectrum & Bretschneider-Mitsuyasu \\
Wave height $H_{o}(\mathrm{~cm})$ & $3.80-12.82$ \\
Wave period $T_{o}(\mathrm{~s})$ & $0.8-2.1$ \\
Wave steepness $H_{o} / L_{o}$ & $0.009-0.06$ \\
Water depth $h(\mathrm{~cm})$ & $40.0,42.5,43.0,45.0$ \\
Sea bottom $\operatorname{slope} \tan \theta$ & $1 / 10,1 / 20,1 / 30$ \\
Seawall slope $\cot \alpha$ & $0.5,3.0$ \\
\hline
\end{tabular}


few runups to define $R_{1 / 3}$.) Figs. $10-12$ indicate that normalized wave runup values are well arranged by the surf similarity parameter. The curves drawn in Figs. 10-12, fitted to the experimental data, are expressed as follows:

$$
\begin{array}{r}
R_{2 \%} / H_{o}=2.99-2.73 \exp \left(-0.57 \cdot \tan \beta / \sqrt{H_{o} / L_{o}}\right) \\
R_{1 / 10} / H_{o}=2.72-2.56 \exp \left(-0.58 \cdot \tan \beta / \sqrt{H_{o} / L_{o}}\right) \\
R_{1 / 3} / H_{o}=2.17-2.18 \exp \left(-0.70 \cdot \tan \beta / \sqrt{H_{o} / L_{o}}\right)
\end{array}
$$

under the conditions that

$$
\begin{aligned}
& 0.2<\tan \beta / \sqrt{H_{o} / L_{o}}<4 \text { approx } \\
& 0.009<\sqrt{H_{o} / L_{o}}<0.06 \\
& -0.37<h / H_{o}<0.53
\end{aligned}
$$

Table 3. Characteristics of New and Mase et al. (2004) Experimental Cases (Values Are in Model Scale)

\begin{tabular}{lccc}
\hline Case & $H(\mathrm{~cm})$ & Bottom slope $(\tan \theta)$ & $\cot \alpha$ \\
\hline 1 & 43.0 & $1 / 10$ & 0.5 \\
2 & 43.0 & $1 / 10$ & 3.0 \\
3 & 43.0 & $1 / 30$ & 0.5 \\
4 & 43.0 & $1 / 30$ & 3.0 \\
5 & 45.0 & $1 / 10$ & 0.5 \\
6 & 45.0 & $1 / 10$ & 3.0 \\
7 & 45.0 & $1 / 30$ & 0.5 \\
8 & 45.0 & $1 / 30$ & 3.0 \\
9 & 40.0 & $1 / 20$ & 0.5 \\
10 & 42.5 & $1 / 20$ & 0.5 \\
11 & 45.0 & $1 / 20$ & 0.5 \\
12 & 40.0 & $1 / 20$ & 3.0 \\
13 & 42.5 & $1 / 20$ & 3.0 \\
14 & 45.0 & $1 / 20$ & 3.0 \\
\hline
\end{tabular}

Fig. 13 summarizes the runup results of Nakamura et al. (1972), denoted in Fig. 13 as $R_{-N a k a m u r a}$, together with all the experimental data shown in Figs. $10-12$ and the values of $R_{50 \%}$. Because the Nakamura et al. (1972) results came from monochromatic wave experiments it was unclear how these results related to random wave conditions. However, by comparing the $R_{-}$Nakamura values with the current study's characteristic values of random wave runup, it appears that $R_{-}$Nakamura roughly corresponds to $R_{50 \%}$; i.e., the runup exceeded by $50 \%$ of the incident waves.

\section{Discussion on Formulas Using Imaginary Slope}

The effectiveness of the imaginary slopes defined in Figs. 5-7 is examined here. Although the seawalls used in the two sets of experiments had uniform slopes of 1:0.5 or 1:3, they were fronted by foreshores on which the waves broke. Here, it is assumed that a composite cross-sectional seawall exists, as shown by the thick line in Fig. 14, and that a wave gauge is installed at the toe of the composite structure.

When the imaginary slope shown in Fig. 5 is used in the prediction formulas [Eqs. (1)-(3)], the predictions agree well with the measurements in which the surf similarity parameter is greater than 0.6 , shown by open circles (the measurements with a 1:10 foreshore slope) in Fig. 15. Using the imaginary slope shown in Fig. 6, the results are plotted in Fig. 16. Here, the agreement between the predictions plotted by the open circles and the measurements is slightly worse.

The solid circles in Figs. 15 and 16 are the measurements from the experimental conditions with a 1:30 foreshore slope in front of the seawall [see Figs. 9(b and c)]. The predictions do not agree well with these measurements and they are not well ordered using the surf similarity parameter and the imaginary slopes defined in Figs. 5 and 6. The definition of imaginary slopes shown in Figs. 5 and 6 may make the imaginary slopes too steep for gentler foreshores. However, the imaginary uniform slope defined in Fig. 7 is clearly effective in summarizing all of the experimental results, as shown in Figs. 10-12.

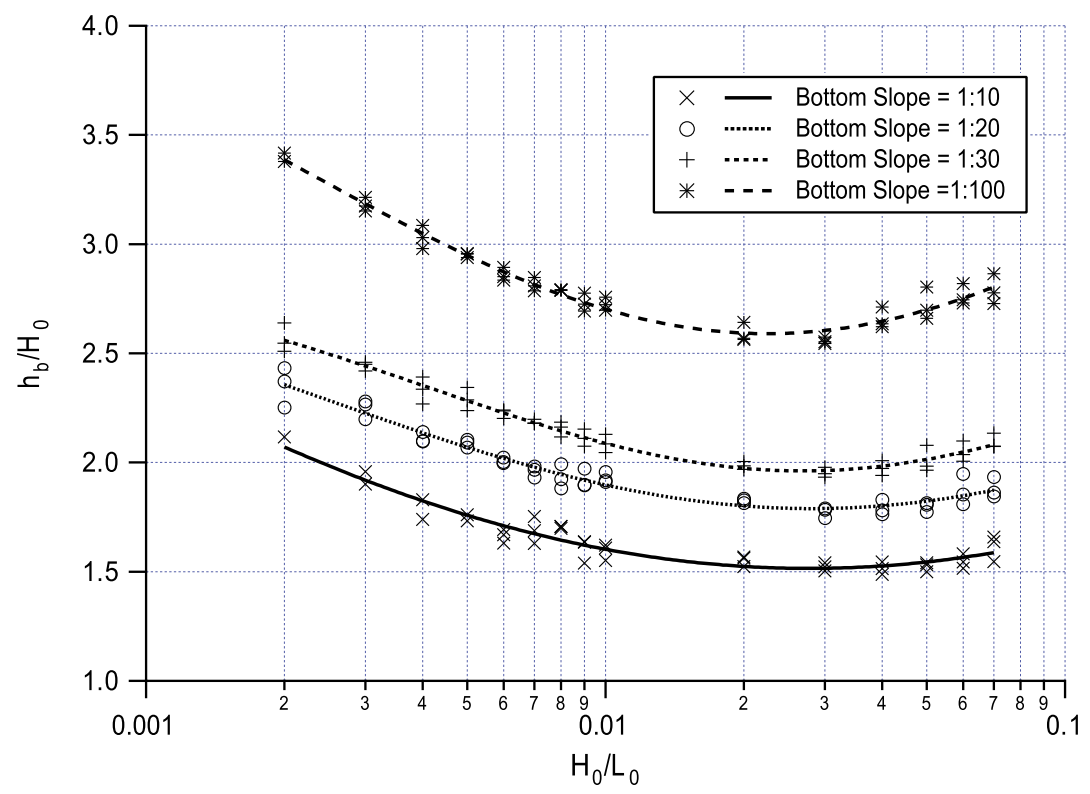

Fig. 8. Nondimensional wave breaking depth against the deepwater wave steepness 


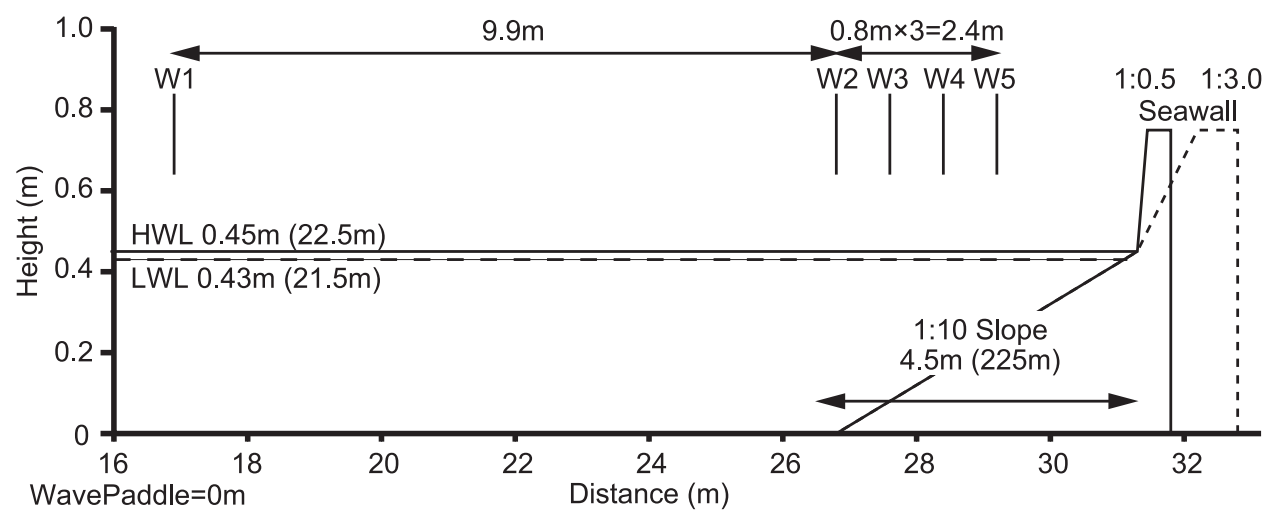

(a) WavePaddle $=0 \mathrm{~m}$

Distance $(\mathrm{m})$

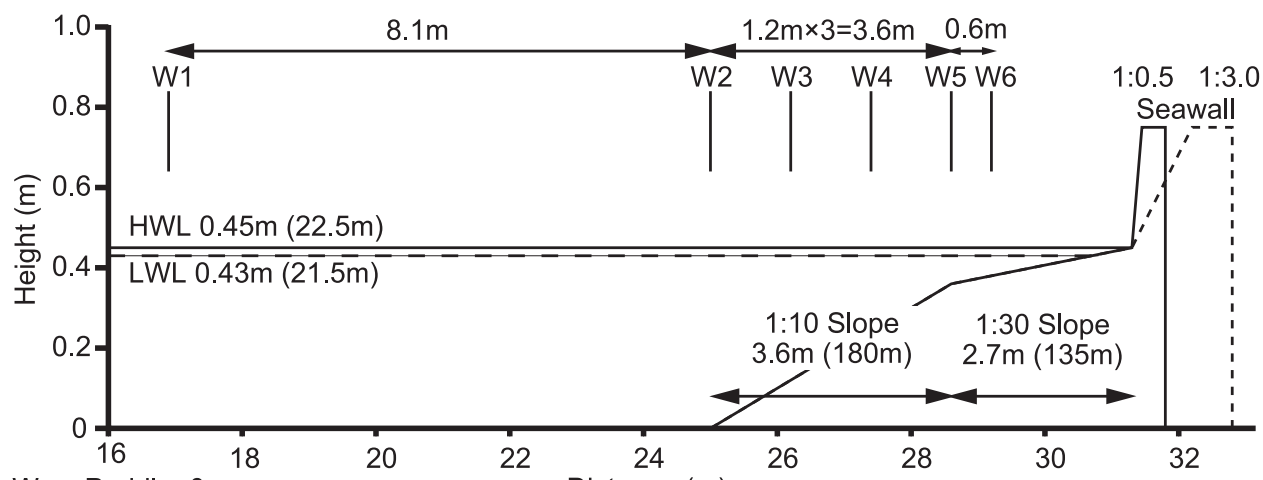

(b) WavePaddle $=0 \mathrm{~m}$

Distance $(m)$

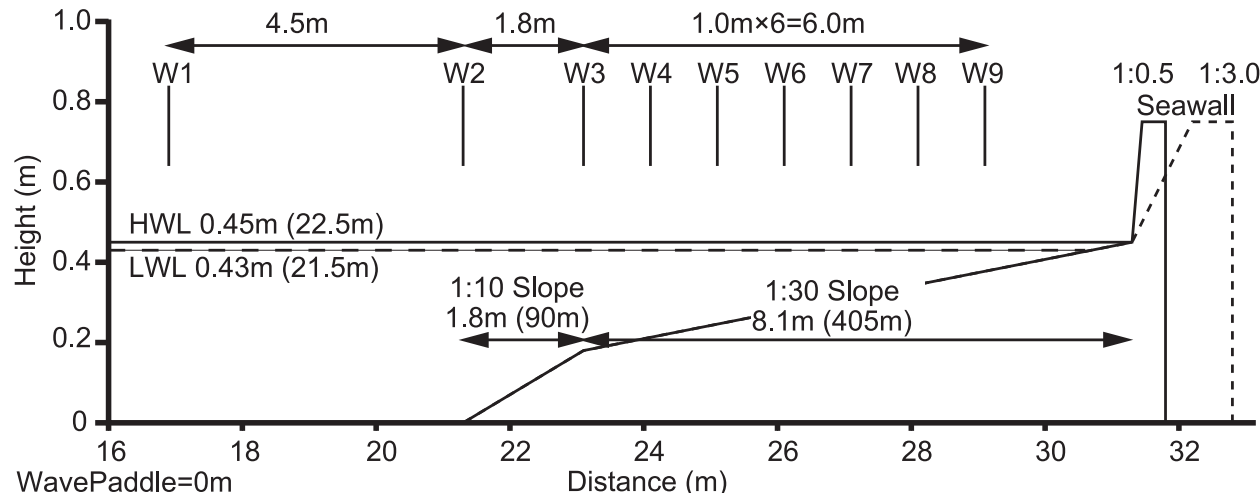

(c) WavePaddle $=0 \mathrm{~m}$

Distance (m)

Fig. 9. Setup used in new experiments (W1-W9 = wave gauges): (a) steep foreshore slope; (b) rapid foreshore slope change; (c) gentle foreshore slope

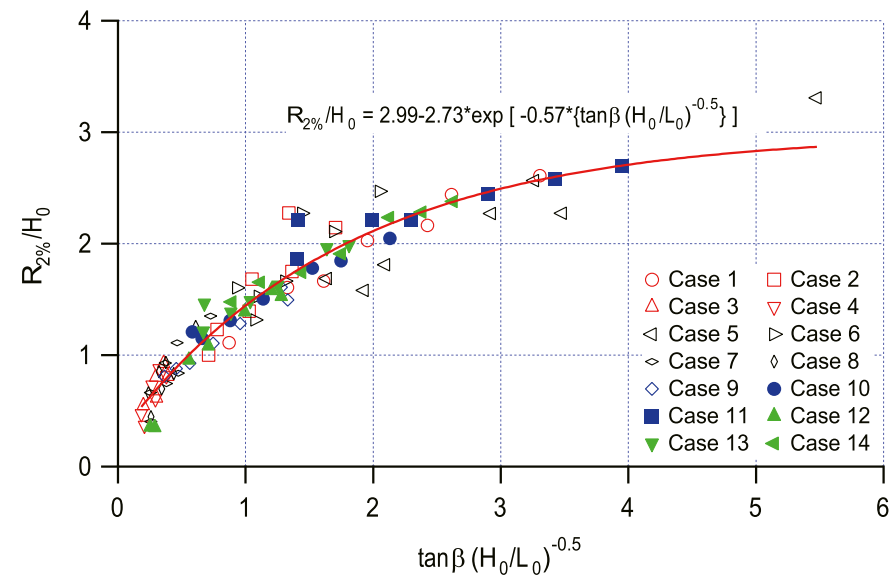

Fig. 10. Nondimensional $R_{2} \%$ runup values as a function of the surf similarity parameter

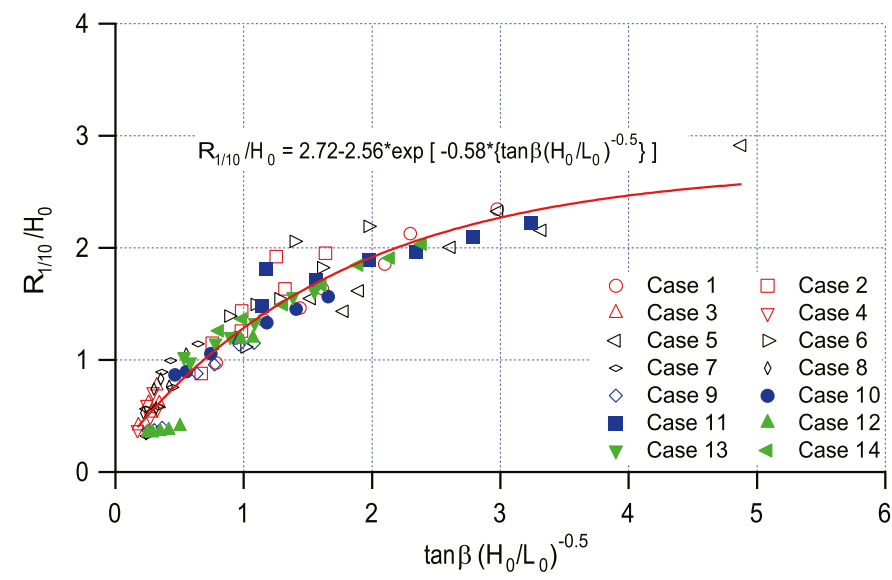

Fig. 11. Nondimensional $R_{1 / 10}$ runup values as a function of the surf similarity parameter 


\section{Wave Overtopping at a Seawall Built on Land and in Very Shallow Water}

\section{Wave Overtopping Formula Combined with Wave Runup}

Because of its proper physical boundary conditions, the Hedges and Reis (1998) formula has been adopted to develop a new procedure

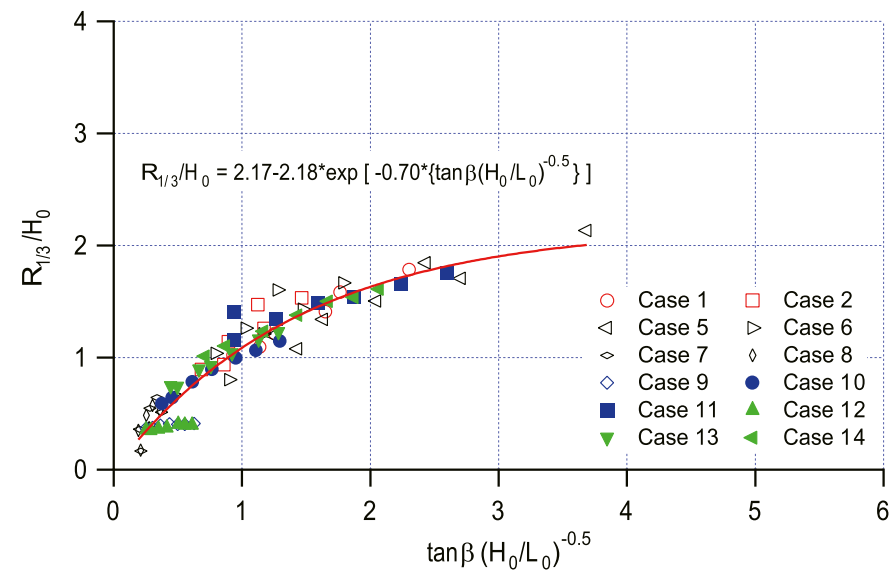

Fig. 12. Nondimensional $R_{1 / 3}$ runup values as a function of the surf similarity parameter

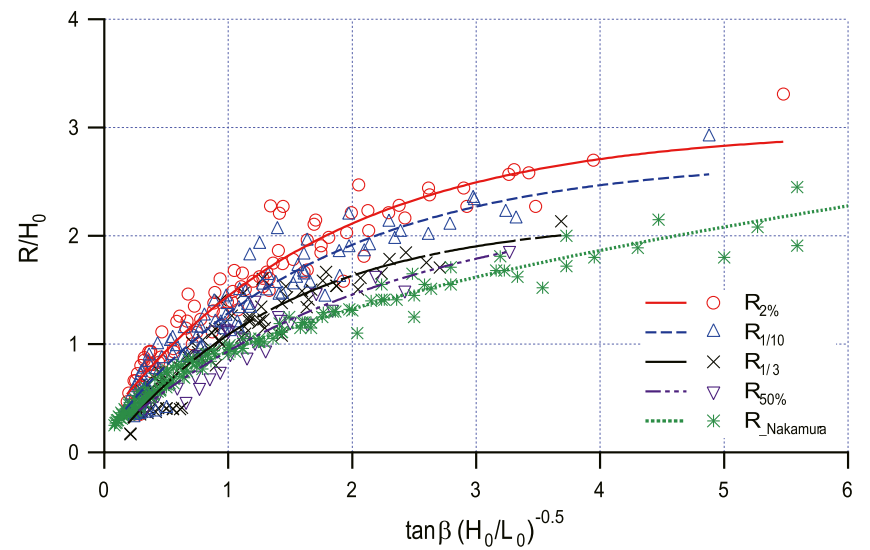

Fig. 13. Summarized Nakamura et al. (1972) results and measured representative runup values for predicting the overtopping at seawalls built on land or in very shallow water. The determination of coefficients $A$ and $B$ is an essential prerequisite to using this formula, and the formulation of $R_{\max }$, which is a probabilistic variable, is another essential precondition. According to Hedges and Reis (1998), the most probable maximum runup during each run of 100 waves, $\left(R_{\max }\right)_{37 \%, 100}$ (i.e., the value not exceeded in $37 \%$ of the cases, assuming a Rayleigh distribution), is given by

$$
\left(R_{\max }\right)_{37 \%, 100} \approx 1.52 R_{1 / 3} \approx 1.09 R_{2 \%}
$$

and the value of the maximum runup not exceeded in $99 \%$ of cases in runs of 100 waves is given by

$$
\left(R_{\max }\right)_{99 \%, 100} \approx 2.15 R_{1 / 3} \approx 1.54 R_{2 \%}
$$

where $R_{2} \%$ has already been formulated by Eq. (9) in this study.

\section{Experimental Data}

Coefficients $A$ and $B$ have been obtained as follows. The experiments by Tamada et al. (2002) were carried out in a wave flume, $25 \mathrm{~m}$ in length, $0.5 \mathrm{~m}$ in width, and $0.6 \mathrm{~m}$ in depth. Seawalls with front slopes of $1: 3,1: 5$, and $1: 7$ were set on a uniform slope of either $1: 10$ or $1: 30$. Random waves conforming to the Bretschneider-Mitsuyasu spectrum were generated with a significant wave period of $1.0 \mathrm{~s}$ and deepwater wave steepnesses, $H_{o} / L_{o}$, of 0.017 and 0.036 . The dimensionless water depths at the toes of the seawalls, $h / H_{o}$, were varied between -0.27 and 0.71 , and the dimensionless crown heights, $R_{c} / H_{o}$, were varied between 0.5 and 1.5 . A total of 300 conditions were tested. The Tamada et al. (2002) experimental data were used by Goda (2009) and are described further in his paper.

Fig. 17 shows the experimental data expressed in the nondimensional forms of $\ln \left(1-R^{*}\right)$ and $\ln Q^{*}\left(Q^{*}=Q / \sqrt{g R_{\max }^{3}}, R^{*}=R_{c} /\right.$ $\left.R_{\max }\right)$, where $\left(R_{\max }\right)_{37 \%, 100}$ is used in Fig. 17(a) and $\left(R_{\max }\right)_{99 \%, 100}$ is used in Fig. 17(b). Because the experimental data could not be represented by a single line, a regression line was drawn to fit the larger portion of overtopping data to provide a conservative estimate for design purposes. Coefficients $A$ and $B$ using $\left(R_{\max }\right)_{37 \%, 100}$ were obtained as

$$
A=0.018, B=3.200
$$

and, using $\left(R_{\max }\right)_{99 \%, 100,}$ they were

$$
A=0.018, B=6.240
$$

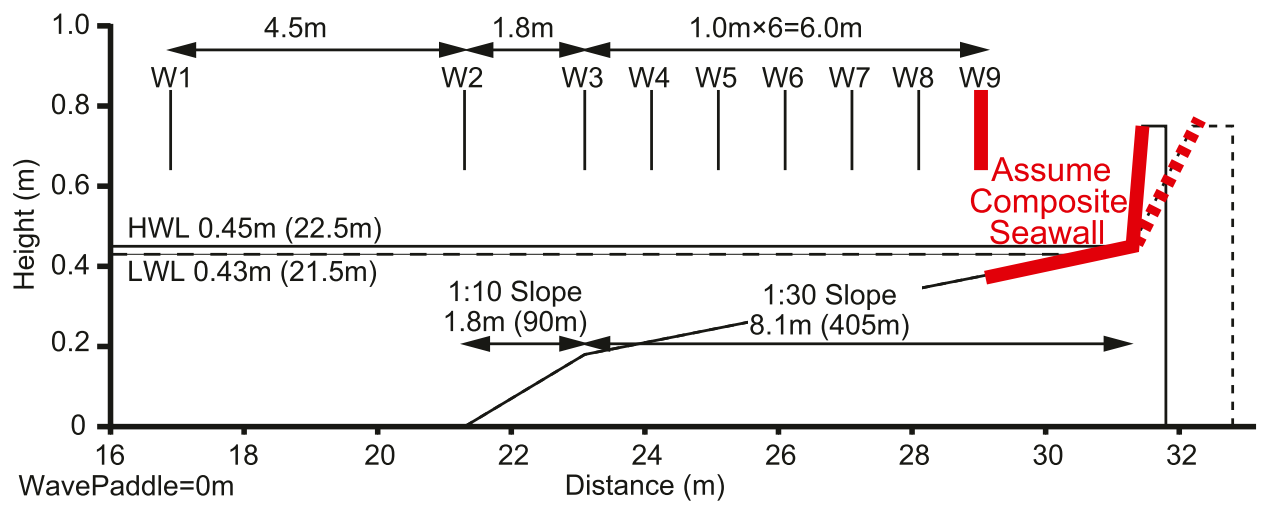

Fig. 14. Assumed composite seawall 


\section{Wave Overtopping Formula}

The following wave overtopping formulas are proposed for seawalls constructed on land or in very shallow water:

$\frac{Q}{\sqrt{g H_{o}^{3}}}= \begin{cases}0.018\left(\frac{R_{\max }}{H_{o}}\right)^{3 / 2}\left[1-\left(\frac{R_{c}}{H_{o}}\right) /\left(\frac{R_{\max }}{H_{o}}\right)\right]^{3.200} \\ \text { for } 0 \leq R_{c}<R_{\max } \\ 0 & \text { for } R_{\max } \leq R_{c}\end{cases}$

with

$$
R_{\max }=1.09 \cdot H_{o}\left[2.99-2.73 \exp \left(-0.57 \cdot \tan \beta / \sqrt{H_{o} / L_{o}}\right)\right]
$$

when using $\left(R_{\max }\right)_{37 \%, 100,}$ and

$$
\frac{Q}{\sqrt{g H_{o}^{3}}}= \begin{cases}0.018\left(\frac{R_{\max }}{H_{o}}\right)^{3 / 2}\left[1-\left(\frac{R_{c}}{H_{o}}\right) /\right. & \left.\left(\frac{R_{\max }}{H_{o}}\right)\right]^{6.240} \\ & \text { for } 0 \leq R_{c}<R_{\max } \\ 0 & \text { for } R_{\max } \leq R_{c}\end{cases}
$$

with

$$
R_{\max }=1.54 \cdot H_{o}\left[2.99-2.73 \exp \left(-0.57 \cdot \tan \beta / \sqrt{H_{o} / L_{o}}\right)\right]
$$

when using $\left(R_{\max }\right)_{99 \%, 100}$.

\section{Comparison between Measured and Predicted Overtopping Discharges}

Fig. 18 compares the Tamada et al. (2002) measurements with the predictions using Eqs. (17) and (18) [Fig. 18(a)] and Eqs. (19) and

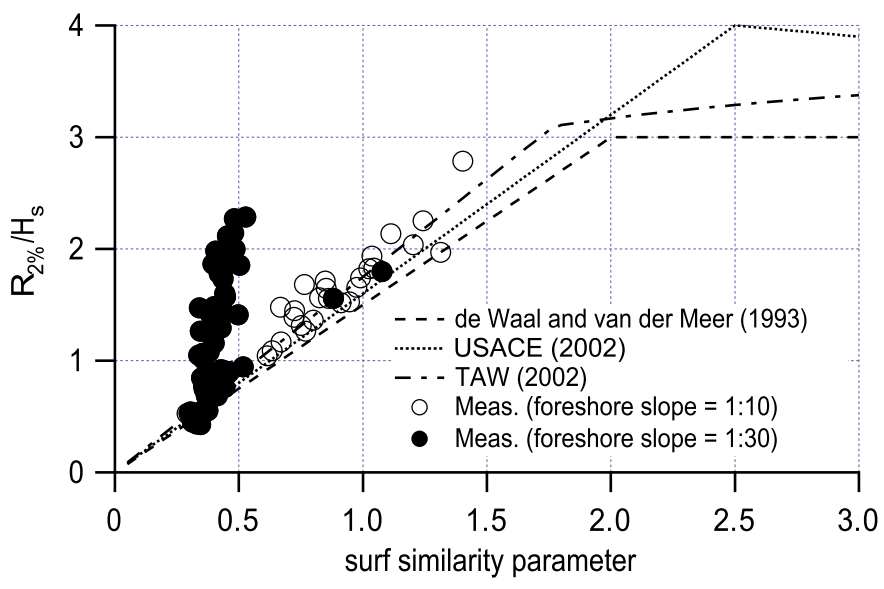

Fig. 15. Predictions $\left(R_{2} \%\right.$ by the three formulas using the imaginary slope defined in Fig. 5
(20) [Fig. 18(b)]. There are three diagonals in Figs. 18(a and b), which correspond to the prediction being 10 times, equal to, and 0.1 times the measured data. Fig. 18 shows that the predictions using $\left(R_{\max }\right)_{99 \%, 100}$ are marginally better than those using $\left(R_{\max }\right)_{37 \%, 100}$, and that both sets of predictions are generally greater than the measured values because of the procedure adopted for determining coefficients $A$ and $B$. A $90 \%$ confidence interval is shown

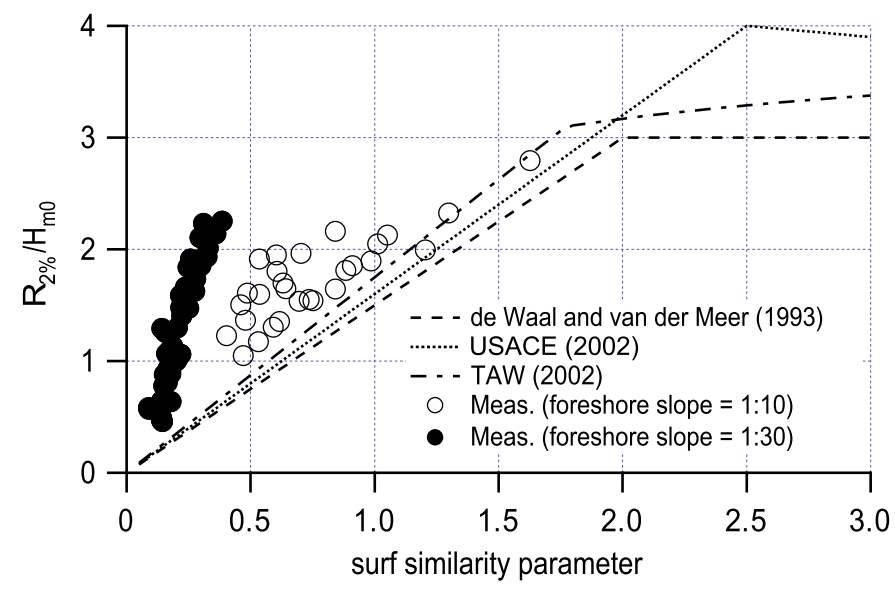

Fig. 16. Predictions $\left(R_{2 \%}\right)$ by the three formulas using the imaginary slope defined in Fig. 6
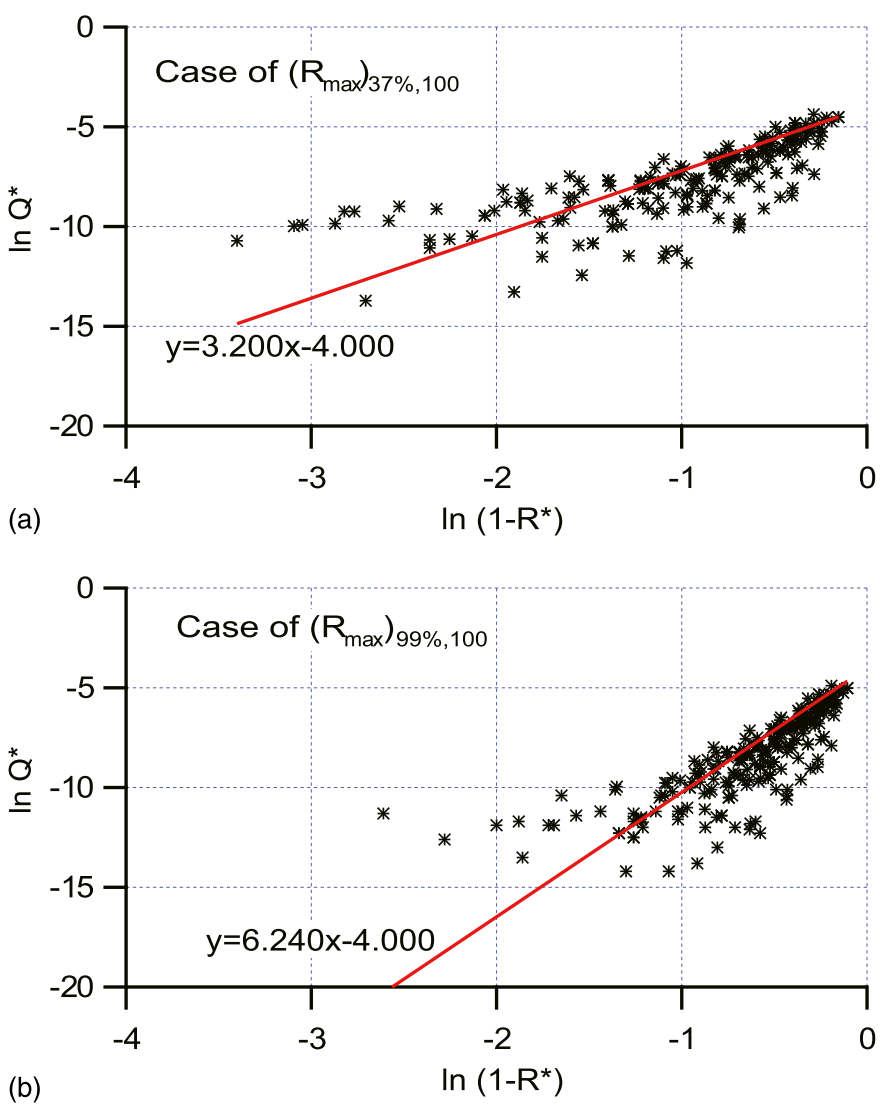

Fig. 17. Experimental data and regression lines to determine coefficients $A$ and $B$ : (a) predictions by Eqs. (17) and (18); (b) predictions by Eqs. (19) and (20) 

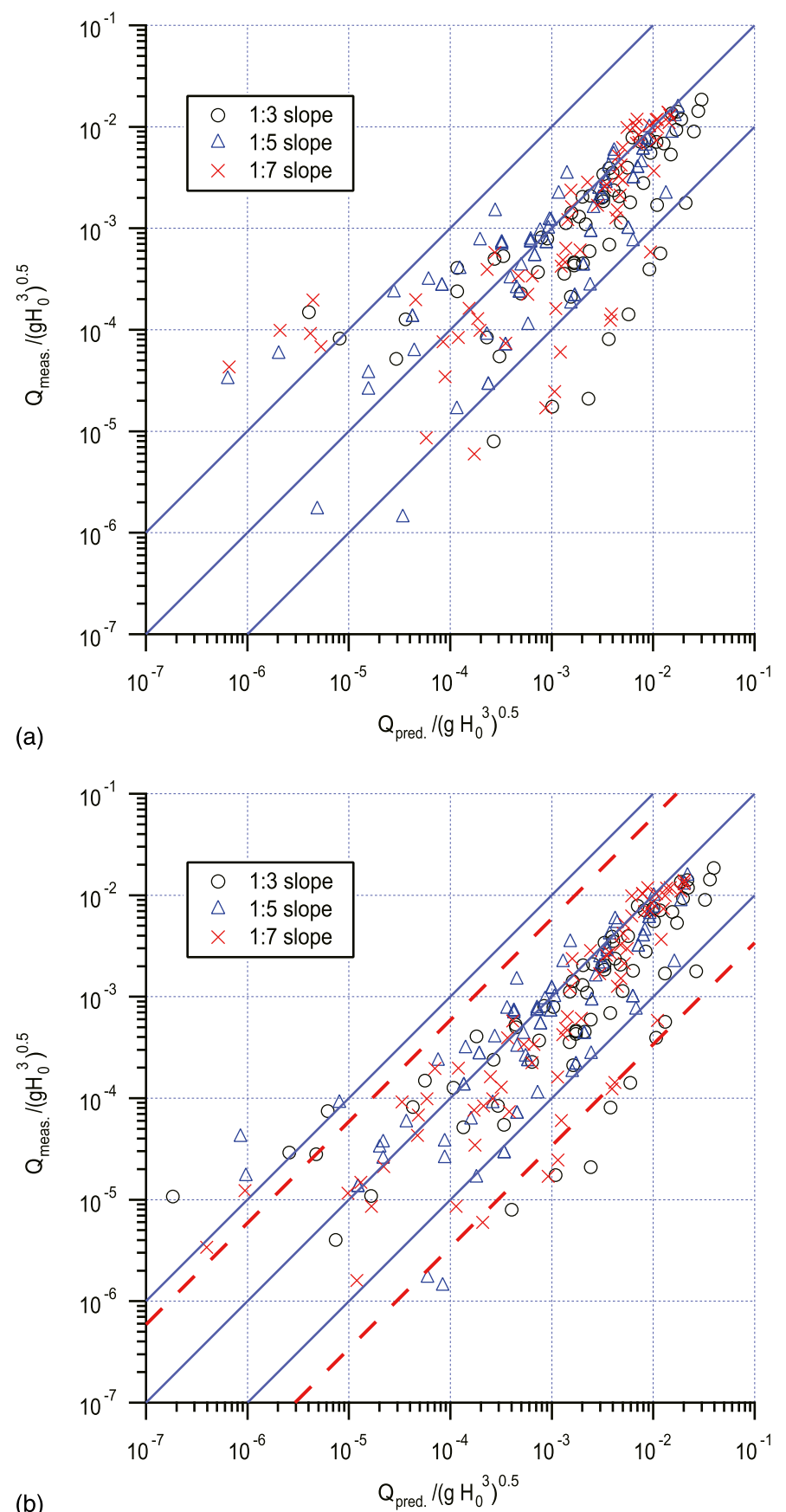

Fig. 18. Comparison of measurements with predictions by the present formulas: (a) predictions by Eqs. (17) and (18); (b) predictions by Eqs. (19) and (20)

in Fig. 18(b) by broken lines, where $5 \%$ of the data are estimated to fall below the interval and 5\% above. The upper limit of the $90 \%$ interval is given by $5.9 \times \mathrm{Eq}$. (19) and the lower limit is given by $0.034 \times$ Eq. (19).

Goda (2009) proposed a new formula for seawalls near shorelines. His formula uses the wave height at the toe of the structure, $H_{s, \text { toe }}$, following Pullen et al. (2007). Because Goda's formula cannot be used to predict the overtopping of seawalls built on land, the Tamada et al. (2002) experimental data with negative water depths at the toes of the seawalls have been removed when comparing the measurements and predictions from Goda's formula and the current
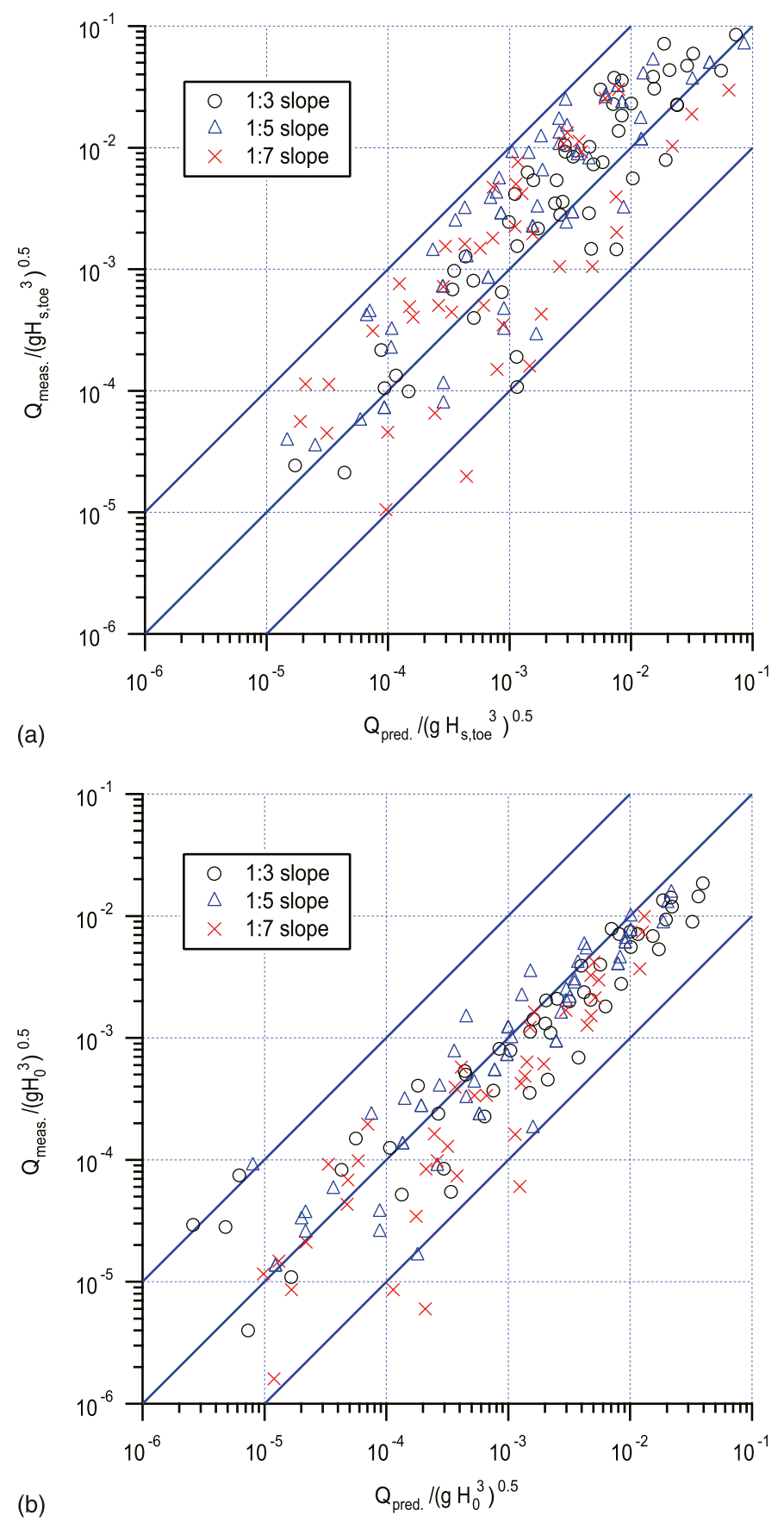

Fig. 19. Comparison of measurements with predictions: (a) Goda's formula; (b) present formula [Eqs. (19) and (20)]

study. Fig. 19(a) compares the Tamada et al. (2002) measurements with predictions using Goda's formula, and Fig. 19(b) shows the results from the present formula using $\left(R_{\max }\right)_{99 \%, 100}$ [Eqs. (19) and (20)]. Fig. 20 displays the ratios of the predicted-to-measured values. It may be seen that the Goda (2009) equation tends to predict smaller values on average, and the ratio is in a range of $10^{-1}$ to 10 times [Fig. 20(a)]. The present formula [Fig. 20(b)] generally provides larger predictions in the range of $Q^{*}>10^{-5}$; and, except for a few points, the ratio of predicted-to-measured values is smaller than for Goda's formula. Fig. 21 summarizes the relationship between the wave runup and the overtopping discharge. The curves drawn in Fig. 21 were obtained using Eqs. (19) and (20). The curves represent the general trend of the measurements very well. 

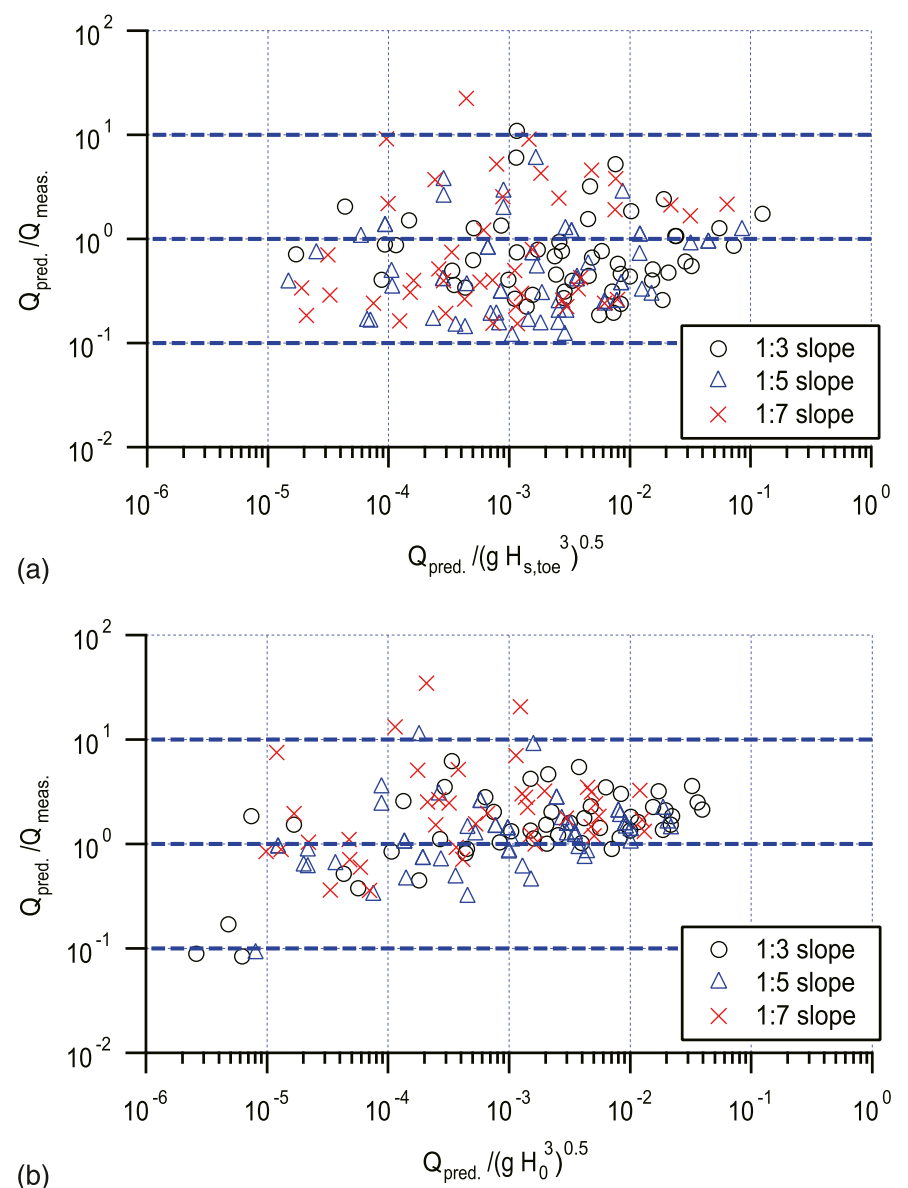

Fig. 20. Ratio of predictions to measurementsc (a) Goda's formula; (b) present formula [Eqs. (19) and (20)]

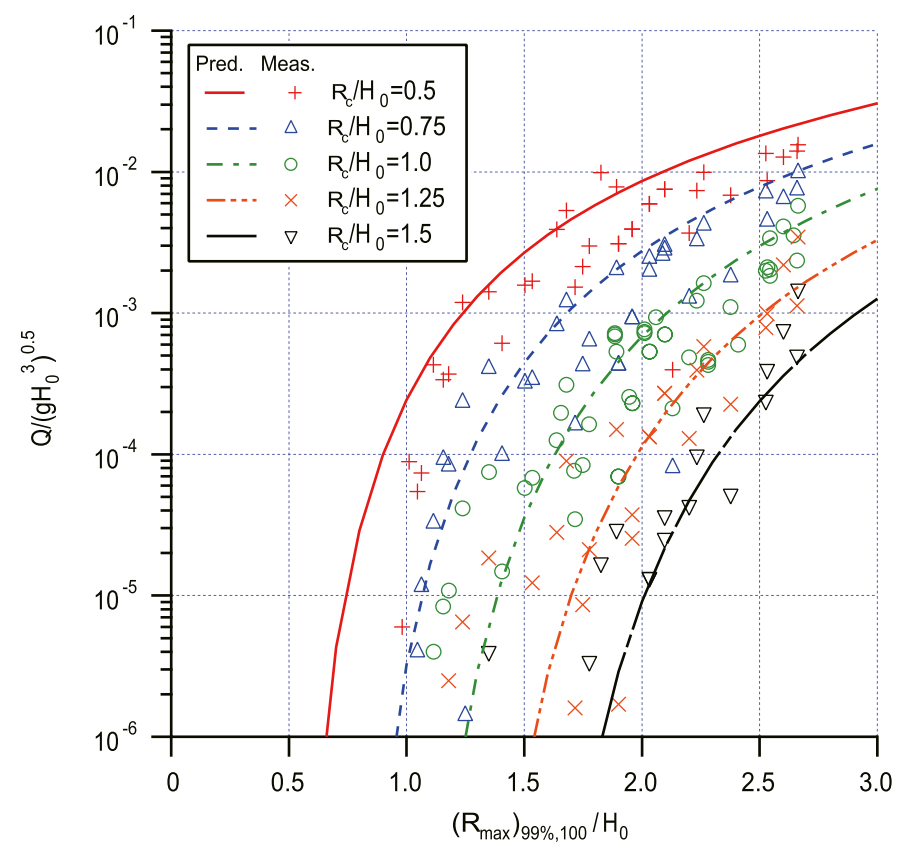

Fig. 21. Relationship between wave runup and wave overtopping

\section{Conclusions}

In Japan, the design of coastal defense structures has not yet been fully unified with regard to the choice of wave overtopping or runup as the governing criterion. When a wall is built in the sea, the design crest level is based on the permissible wave overtopping discharge; however, when it is constructed on the shore, the required crest level is determined by the wave runup, according to the current Japanese technical standards.

The current study introduces random wave runup formulas for seawalls constructed on land or in very shallow water. Although several existing formulas use the wave characteristics at the toes of the seawalls as input, the current study has adopted deepwater wave characteristics and an imaginary uniform slope because of their easy application to seawalls built on land. In addition, a formula for wave overtopping was established using the runup predictions. For the wave runup prediction formulas, two sets of experimental data have been used: a new set of data and the Mase et al. (2004) data. For the wave overtopping prediction formulas, the experimental data of Tamada et al. (2002) have been used. A comparison with measurements shows good performances for the new wave runup and overtopping formulas. A diagram showing the relationship between wave runup and wave overtopping was given, using the proposed formulas, and the diagram represents the general trend of the measurements very well.

\section{Acknowledgments}

Part of this study was supported by a fund from The Service Center of Port Engineering and Grant-in-Aid for Scientific Research by the Ministry of Education, Culture, Sports, Science, and Technology (MEXT), Japan. The authors express their particular gratitude to Emeritus Professor M. Inoue and his former students of Kansai University who have completed more than 300 wave overtopping experiments and willingly provided the authors with their valuable data.

\section{Notation}

The following symbols are used in this paper:

$$
\begin{aligned}
A, B= & \text { empirical coefficients in the wave } \\
& \text { overtopping formulas; } \\
\mathrm{A}_{\text {rea }}= & \text { cross-sectional area of seawall and } \\
& \text { foreshore between the wave breaking location } \\
& \text { and the runup level (Fig. } 7) ; \\
c= & \text { coefficient in Eq. (4); } \\
\cot \alpha= & \text { cotangent of the seawall front slope; } \\
g= & \text { gravitational acceleration; } \\
H_{\mathrm{m} 0}= & \text { spectral significant wave height at the toe } \\
& \text { of the structure; } \\
H_{o}= & \text { offshore significant wave height; } \\
H_{o} / L_{o}= & \text { deepwater significant wave steepness; } \\
H_{s}= & \text { significant wave height at the toe of the } \\
& \text { structure or at the toe of a foreshore sloping } \\
& \text { uniformly seaward to a depth unaffected by } \\
& \text { wave breaking; } \\
H_{\mathrm{s}, \text { toe }}= & \text { significant wave height at the toe of } \\
& \text { a structure in the Goda (2009) formula; } \\
h= & \text { water depth in hydraulic experiments; } \\
h_{b}= & \text { water depth at wave breaking; } \\
L_{o}= & \text { deepwater wavelength associated with the } \\
& \text { offshore significant wave period, } \\
& T_{o}\left(=g T_{o}^{2} / 2 \pi\right) ;
\end{aligned}
$$


$Q=$ mean overtopping discharge per unit length of seawall;

$Q^{*}=$ dimensionless mean overtopping discharge per unit length of seawall;

$Q_{\text {meas. }}=$ measured overtopping discharge;

$Q_{\text {pred. }}=$ predicted overtopping discharge;

$R=$ runup of regular waves;

$R_{c}=$ seawall freeboard;

$R^{*}=$ dimensionless seawall freeboard;

$R_{\text {char }}=$ value characterizing the magnitude of the runups, such as $R_{2}, R_{1 / 10}$, or $R_{1 / 3}$;

$R_{\max }=$ maximum runup;

$\left(R_{\max }\right)_{37 \%, 100}=$ value of the maximum runup not exceeded in $37 \%$ of the cases during runs of 100 waves, assuming a Rayleigh distribution;

$\left(R_{\max }\right)_{99 \%, 100}=$ value of the maximum runup not exceeded in $99 \%$ of the cases during runs of 100 waves, assuming a Rayleigh distribution;

$R_{1 / 3}=$ average of the highest one-third of the runups;

$R_{1 / 10}=$ average of the highest one-tenth of the runups;

$R_{2} \%=$ runup exceeded by $2 \%$ of the incident waves;

$R_{50 \%}=$ the runup exceeded by $50 \%$ of the incident waves;

$S_{\text {char }}=$ minimum value of $R_{\text {char }}$ as the front slope approaches zero;

$T_{m}=$ mean zero-crossing wave period;

$T_{m-1,0}=$ spectral-based wave period; $T_{m-1,0} \approx T_{p} / 1.1$;

$T_{o}=$ offshore significant wave period;

$T_{p}=$ spectral peak period;

$\tan \beta=$ tangent of the imaginary slope;

$\tan \theta=$ tangent of the sea bottom slope;

$\alpha=$ angle of the seawall front slope measured from the horizontal;

$\beta=$ imaginary (or equivalent) slope angle of the combined seawall and foreshore measured from the horizontal;

$\xi_{m}=$ surf similarity parameter defined using $H_{m 0}$ and $T_{m-1,0}$; and

$\xi_{p}=$ the surf similarity parameter defined using $H_{s}$ and $T_{p}$.

\section{References}

de Waal, J. P., and van der Meer, J. W. (1993). "Wave run-up and overtopping on coastal structures" Proc. 23rd Int. Conf. on Coastal Eng., 1992, ASCE, New York, 1758-1771.

Goda, Y. (2000). Random seas and design of maritime structures, World Scientific, Singapore.

Goda, Y. (2009). "Derivation of unified wave overtopping formulas for seawalls with smooth, impermeable surfaces based on selected CLASH datasets." Coastal Eng., 56(4), 385-399.

Goda, Y., Kishira, Y., and Kamiyama, Y. (1975). "Laboratory investigation on the overtopping rate of seawalls by irregular waves." Rep. Port Harbour Res. Inst., 14(4), 3-44 (in Japanese).
Hedges, T. S., and Mase, H. (2004). "Modified Hunt's equation incorporating wave setup." J. Waterway, Port, Coastal, Ocean Eng., 130(3), 109-113.

Hedges, T. S., and Reis, M. T. (1998). "Random wave overtopping of simple sea walls: A new regression model." Proc. Inst. Civ. Eng., Water Maritime Energ., 130(1), 1-10.

Hedges, T. S., and Reis, M. T. (2004). "Accounting for random wave run-up in overtopping predictions." Proc. Inst. Civ. Eng., Maritime Eng., 157(3), 113-122.

Kikkawa, H., Shiigaki, H., and Kono, T. (1968). "Fundamental study of wave over-topping on levees." Coast. Eng. Japan, 11, 107-115.

Mase, H., Hedges, T. S., Shareef, M., and Nagahashi, S. (2003). "Wave overtopping formula for gentle slopes incorporating wave runup." Proc., Coastal Eng. JSCE, 50, 636-640 (in Japanese).

Mase, H., and Iwagaki, Y. (1985). "Runup of random waves on gentle slopes." Proc. ,19th Int. Conf. on Coastal Engineering, ASCE, Reston, VA, 593-609.

Mase, H., and Kirby, J. T. (1993). "Hybrid frequency-domain KdV equation for random wave transformation." Proc., 23rd Int. Conf. on Coastal Engineering, ASCE, New York, 474-487.

Mase, H., Miyahira, A., and Hedges, T. S. (2004). "Random wave run-up on seawalls near shorelines with and without artificial reefs." Coast. Eng. Japan, 46(03), 247-268.

Nakamura, M., Sasaki, Y., and Yamada, J. (1972). "Runup on seawalls with composite cross section.” Proc., JSCE, 19, 309-312 (in Japanese).

National Association of Sea Coast (NASC). (1982). Compilation of examples of shore protection facilities, NASC, Tokyo, 1-70 (in Japanese).

Owen, M. W. (1980). "Design of seawalls allowing for wave overtopping." Rep. EX924, Hydraulics Research Station, Wallingford, U.K.

Pullen, T., Allsop, N. W. H., Bruce, T., Kortenhaus, A., Schuttrumpf, H., and van der Meer, J. W., eds. (2007). EurOtop-Wave overtopping of sea defences and related structures: Assessment manual, 〈http://www .overtopping-manual.com/manual.html $>$ (Aug. 2008).

Reis, M. T., Hu, K., Hedges, T. S., and Mase, H. (2008). "A comparison of empirical, semiempirical, and numerical wave overtopping models." J. Coastal Res., 24(2A), 250-262.

River Bureau of Japan (RBJ). (1990). Coastal engineering for practitioners, Seacoast Division, Ministry of Construction, River Bureau, Tokyo (in Japanese).

Saville, T., Jr. (1958). "Wave run-up on composite slopes." Proc., 6th Int. Conf. on Coastal Engineering, ASCE, Reston, VA, 691-699.

Takayama, T., Nagai, T., and Nishida, K. (1982). "Decrease of wave overtopping amount due to seawalls of low crest types." Rep. Port Harbour Res. Inst., 21(2), 151-205.

Tamada, T., Inoue, M., and Tezuka, T. (2002). "Diagrams for the estimation of wave overtopping rate on gentle slope-type seawalls." Proc., Coastal Eng. JSCE, 49, 641-645 (in Japanese).

Tamada, T., Mase, H., and Yasuda, T. (2009). "Random wave runup formulae for seawall with composite cross section.” JSCE, Ser. B2 (Coast. Eng.), 65(1), 936-940 (in Japanese).

Technical Advisory Committee on Flood Defence (TAW). (2002). Technical report wave run-up and wave overtopping at dikes, J. W. Van der Meer, ed., TAW, Delft, Netherlands.

The Overseas Coastal Area Development Institute of Japan (OCDI). (2007). Technical standards and commentaries for port and harbour facilities in Japan, OCDI, Tokyo (in Japanese).

Tominaga, M. (1972). "Experimental study on hydraulics of breakwaters." Technical Note No.766, Public Works Research Institute, Ibaraki, Japan, 6-15 (in Japanese).

U.S. Army Corps of Engineers (USACE). (2002). Coastal engineering manual, EM 1110-2-1100, USACE, Washington, DC.

van der Meer, J. W., and Janssen, J. P. F. M. (1995). "Wave run-up and wave overtopping at dikes." Wave forces on inclined and vertical wall structures, N. Kobayashi and Z. Demirbilek, eds., ASCE, New York, $1-27$. 